\title{
Combined Approach Using Capillary Electrophoresis and Molecular Modeling for an Understanding of Enantioselective Recognition Mechanisms
}

\author{
Abdalla A. Elbashir \\ University of Khartoum, Faculty of Science, Chemistry Department, Khartoum, 11115, Sudan \\ Abstract: Many molecular modeling methods have been recently proposed as powerful tools to obtain information about \\ the emerging interaction of inclusion complexes between chiral selectors and enantiomers and then to elucidate chiral \\ recognition processes. In this review the contribution of chiral capillary electrophoresis in combination with molecular \\ modeling to a better understanding of the chiral recognition mechanisms with CDs as chiral selectors will be discussed.
}

Keywords: Capillary electrophoresis, chiral separation, Molecular modeling, recognition mechanism.

\section{INTRODUCTION}

Chiral recognition is attracting increasing attention owing to the enormous importance in many fields such as drug discovery, life sciences, food science, and agrochemicals and also in environmental studies. Of a particular importance is the significant impact of chirality in pharmaceutical research. More than half of the currently developed drugs possess one or more chiral centers. Moreover, the majority of these drugs are prescribed and used as racemates [1]. The general perception is that one enantiomer may possess the desired pharmacological effects while the other is of a lower potency or even inactive. However, for many drug candidates, the effect of individual enantiomers on the pharmacodynamics or the pharmacokinetics remains unraveled.

Since the 1980s capillary electrophoresis (CE) techniques have emerged as powerful tools in enantiomeric separation due to their simplicity, high efficiency and versatility [2-4]. In CE chiral selectors of various types are added to the background electrolyte (BGE). Electrophoretic methods usually separate charged species in an electric field due to differences in sizes and charges which will lead to different mobilities $[2,5]$. Enantiomers of a chemical species possess similar charges and the same size, therefore are expected not to be separated by electrophoretic techniques.

The theoretical basis for the mechanism of separations involving chiral selectors added to the background electrolyte in CE methods is well

${ }^{*}$ Address corresponding to this author at the University of Khartoum, Faculty of Science, Chemistry Department, Khartoum, 11115, Sudan;

Tel: 00249912989405; E-mails: hajaae@yahoo.com, aaelbashir@uofk.edu documented in the literature [6-10]. The major requirement for enantioseparation in $\mathrm{CE}$ is believed to be the complexation between the enantiomeric analyte and the chiral selector. The mass-to-charge ratio governs the movement of the free analyte, the selector and the analyte-selector complex towards the detector. Clearly the mobilities of the free enantiomers are equal; therefore complexation between the analyte and the chiral selector must result in change in the effective mobilities of analytes. Therefore, formation of transient diastereomeric complexes of different binding constants may lead to different mobilities. The time for which the enantiomers reside in the free and complexed form is determined by the strength of intermolecular interactions between the analyte and the chiral selector. Furthermore different mobilities of the diastereomeric complexes may originate form differences in the fit of guests into the host resulting in differences in the shapes and net charges of these complexes [2, 6-9].

Recently, there has been an increase in interest in molecular modeling studies on the formation and stability of inclusion complexes of cyclodextrins with a variety of molecules and other aspects of supramolecular chemistry. Various theoretical approaches have been applied in these studies such as molecular mechanics, molecular dynamics, semiempirical methods, as well as hybrid techniques such as quantum-mechanics-molecular mechanics (QM-MM) techniques [10-25]. Hartree-Fock (HF) and density functional theory (DFT) calculations especially using the popular B3LYP functional combined with different standard basis set have been used reliably to describe host guest interactions of CDs with several molecules [26-31]. Despite this rapid development and use of ab initio and DFT semiempirical methods still attract great deal of attention owing to their less 
computational demands. The recently introduced semiempirical PM6 method has been found to give more accurate estimates of molecular properties comparable to HF and DFT methods at even lower computational cost, making it an attractive method for the description of inclusion complexes [26]. Of special interest to molecular modeling studies are those associated with the enantioseparations of chiral molecules using the supramolecular chemistry. These studies aimed to rationalize and predict the experimental results obtained using different chromatographic separation techniques such as capillary electrophoresis, gas chromatography and liquid chromatography.

Molecular modeling has been considered as an essential tool for elucidating mechanisms of molecular chiral recognition. Molecular modeling studies about enantiomer separation by liquid chromatography using various CSPs including donor-acceptor (Pirkle-type), polysaccharide, cyclodextrin, chiral ligand exchange, and protein CSPs had been reported and reviewed [3239]. In this review chiral recognition mechanism using capillary electrophoresis and molecular modeling approach will be discussed.

\section{CAPILLARY ELECTROPHORESIS MOLECULAR MODELING STUDIES}

AND

Bednarek et al. [40, 41] used NMR and molecular modeling for investigations the host-guest complexation of R- or S-linezolid with HDAS- $\beta$-CD. The stereoselective interactions were analyzed by the molecular modeling results. The stereoselectivity is based on inclusion complexation where the main orientations of linezolid are that with oxazolidinone part immersed in HDAS- $\beta-C D$ cavity.

Parametric Method 3 semiempirical molecular orbital calculations have also been used to rationalize the CE enantioseparations of salsolinol, N-methylsalsolinol, and 1-benzyltetrahydroisoquinoline by -CD [42]. Migration order deduced from the study of capillary electrophoretic separation is very well with the theoretical result.

Molecular modeling studies were also used to understand the interaction between cathecin enantiomers and mono-succinyl- $\beta-C D$ [43]. The stabilization energies of the inclusion complexes correlated with the enantiomer migration order observed in CE.

Chiral ligand exchange CE was applied to the separation of the enantiomers of underivatized amino acids. Chiral discrimination is based on the formation of ternary complexes between copper (II), a chiral selector (L-proline or trans-4-hydroxy-L-proline) and an amino acid [44, 45]. The formation constants of the formed diastereoisomeric ternary complexes are consistent with those obtained by molecular mechanics calculations.

A set of 25 triadimenol analogs for the analysis of the chiral recognition mechanism by carboxymethyl- $\beta$ $C D(C M-\beta-C D)$ was reported [46]. The chiral separation of 20 compounds were achieved by using $5 \mathrm{mM}$ of CM$\beta-C D$ in $30 \mathrm{mM}$ sodium dihydrogen phosphate, $\mathrm{pH} 2.2$, and a voltage of $20 \mathrm{kV}$ at $20 \circ \mathrm{C}$. Molecular docking was carried out for each compound and CM- $\beta-C D$ indicated that a hydrophobic interaction and two hydrogen bonds were involved in the interaction between the $C D$ and the triadimenol enantiomers. A mathematical model was established correlating the interaction energies of the molecular docking calculations and the resolution found in the CE chiral separation. The model could be used to predict the enantioseparation of a triadimenol analog.

The $1 \mathrm{H}$ NMR titration and capillary electrophoresis were also applied to study the inclusion complex formation of aspartame (guest) and various cyclodextrins (host) [47]. The interaction molecular modeling calculations were also carried out to confirm the structure and to compare complexation of the guest with different CDs.

Molecular modeling study was applied to understand the interaction between aminoglutethimide (AGT) enantiomers and methyl- $\beta-C D$ by Elbashir et al., [48]. The computational calculations for the inclusion complexes for AGT enantiomers and M- $\beta$-CD were performed. The results of these calculations showed the difference in the stability of these complexes lead to different migration times of the AGT enantiomers in CE.

Elbashir and coworkers have also performed PM3 semiemperical molecular orbital calculations on the inclusion complexes formed between the cyclodextrins and 18-crown-6 with primaquine $(P Q)$ or quinocide (QC) $[49,50]$. Theoretical calculation revealed that the $\beta$-CD-PQ complex is significantly more stable than the $\beta-C D-Q C$ inclusion complex by an energy difference of $25.5 \mathrm{~kJ} / \mathrm{mol}$. This indicates that $P Q$ fits more tightly into the cavity of $\beta-C D$ according to the theoretical calculations, Figure 1.

CE method for the determination and quantification of modafinil enantiomers was developed [51]. The 


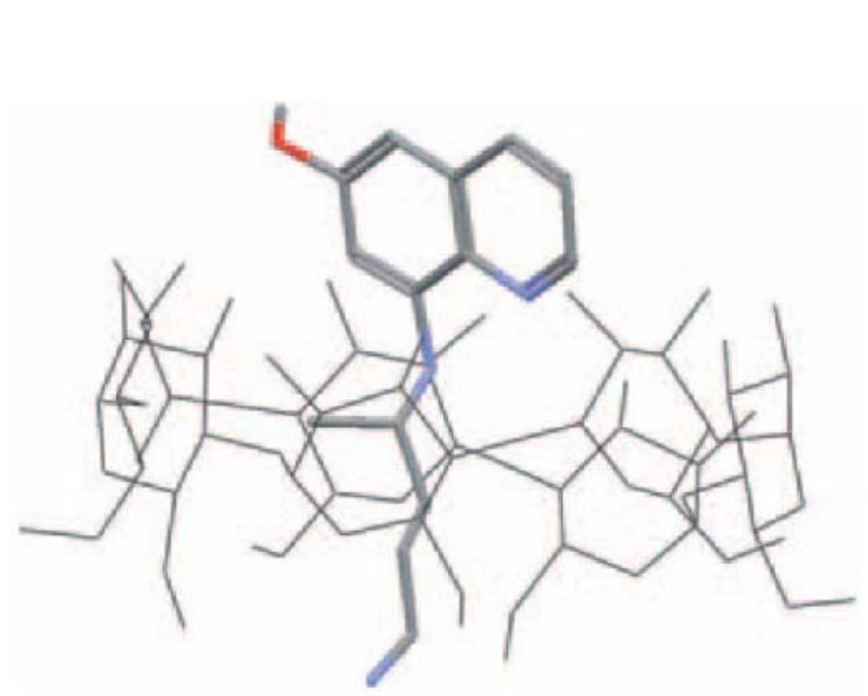

a

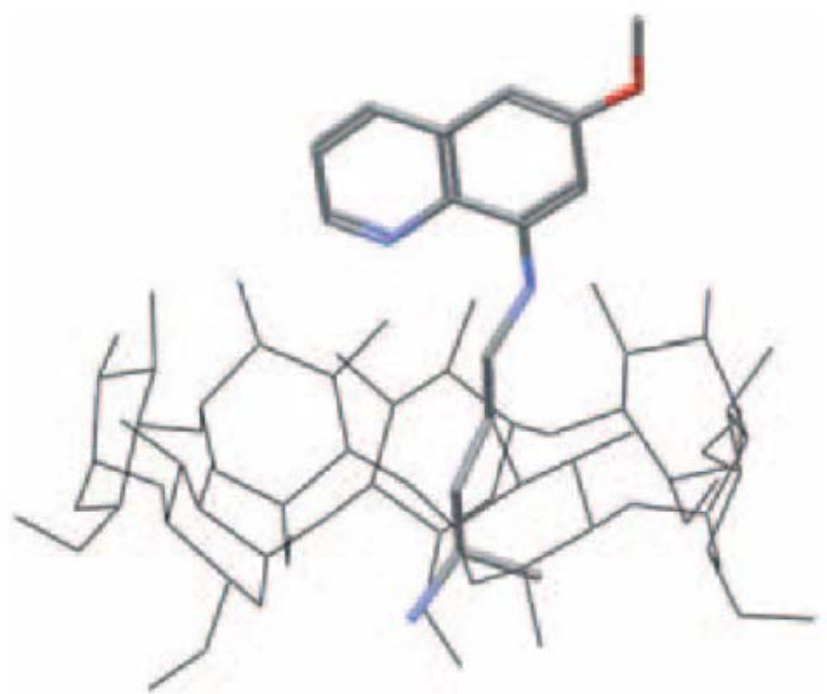

b

Figure 1: Structure of (a) PQ- $\beta-C D$ and (b) QC- $\beta-C D$ complexes with the minimum energy obtained from PM3 calculations

computational calculations for the enantiomeric inclusion complexes rationalized the reasons for the different migration times between the modafinil enantiomers.

Simultaneous chiral separations of ofloxacin and ornidazole enentiomers were achieved using sulfated$\beta$-cyclodextrin (S- $\beta-C D)$ as a chiral selector [52]. Computational calculations for the inclusion complexes with $S-\beta-C D$ showed that the differences in the stability of these complexes lead to different migration times of ofloxacin and ornidazole enantiomers.

Affinity capillary electrophoresis (ACE) method for the determination of the stability constants for the interaction between $\alpha$-CDs and 2-hydroxypropyl- $\alpha$ cyclodextrin and glyco- and tauro conjugated bile salts was developed [53]. Molecular modeling calculation was conducted and demonstrated that the interaction between the two species involves the side chain of the bile salt.

The use of capillary electrophoresis for the separation of enantiomers of primary amines, namely 1,2,3,4-tetrahydro-1-naphthylamine (THAN), 1- (1naphtyl)ethylamine (NEA) and 1-aminoindan (AI) with $\beta$-CD alone and with $\beta$-CD in presence of 18-crown-6 was described by Elbashir and Suliman [54]. The mechanism of enantiodifferentiation was investigated using molecular mechanics and the semiempirical method PM6. The theoretical calculations suggested that the presence of $18 \mathrm{C} 6, \beta-C D$ system leads to the formation of stable sandwich compounds with protonated primary amines, Figure 2.
Chiral separations of five $\beta$-adrenergic antagonists were achieved by $C E$ using $C M-\beta-C D$ as the chiral selectors [55]. The course of host-guest inclusion was investigated by molecular docking technique. Hydrogen bonding between $C M-\beta-C D$ and $\beta$-adrenergic antagonists played an important role in the process of enantionseparation and a model of the hydrogen bonding interaction positions was constructed.

Li et al., $[56,57]$ have developed and validated CE method for enantiomeric separation of iodiconazole and 12 new structurally related potent triadimenol analogues using hydroxypropyl- $\gamma$-cyclodextrin (HP- - $\mathrm{CD}$ ) as the chiral selectors. Based on the results of molecular mechanics calculations mathematical equation was constructed to predict the theoretical resolution of enantioseparation.

Chiral separation of bupivacaine and propranolol as model compounds were investigated by nonaqueous CE (NACE) with two single-isomer highly charged $\beta$ $C D$ derivatives, namely heptakis(2,3-di- O-methyl-6- Osulfo)- $\beta-C D$ (HDMS- $\beta-C D)$ and heptakis(2,3-di-Oacetyl-6- O-sulfo)- $\beta$-CD (HDAS- $\beta$-CD), [58]. Molecular modeling study was carried out and the interaction energies calculated for bupivacaine and propranolol correlated with the enantiomer migration order observed in the NACE experiments using both anionic $\mathrm{CD}$ derivatives.

Recently Suliman and Elbashir [59] have investigated the chiral separation of baclofen enantiomers using CE with $\beta$-cyclodextrin $(\beta-C D)$ as a chiral selector. Dockings based on molecular 


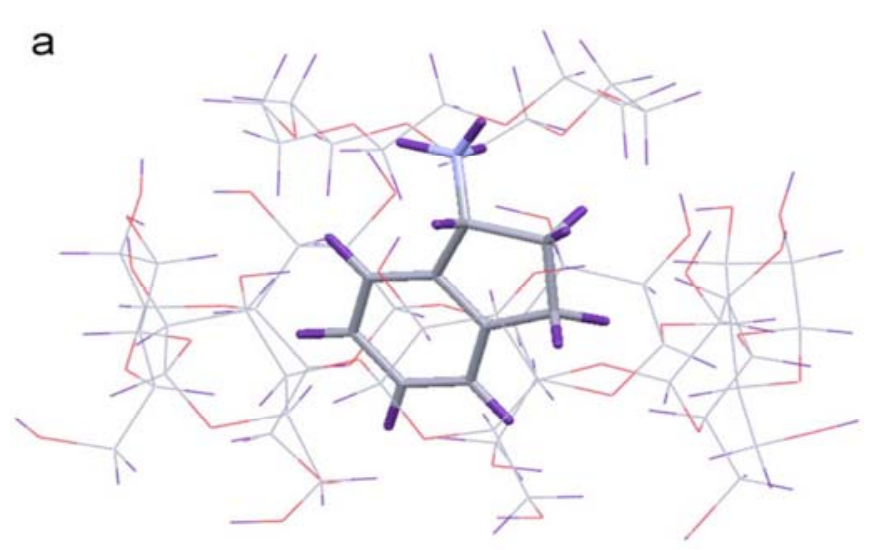

b

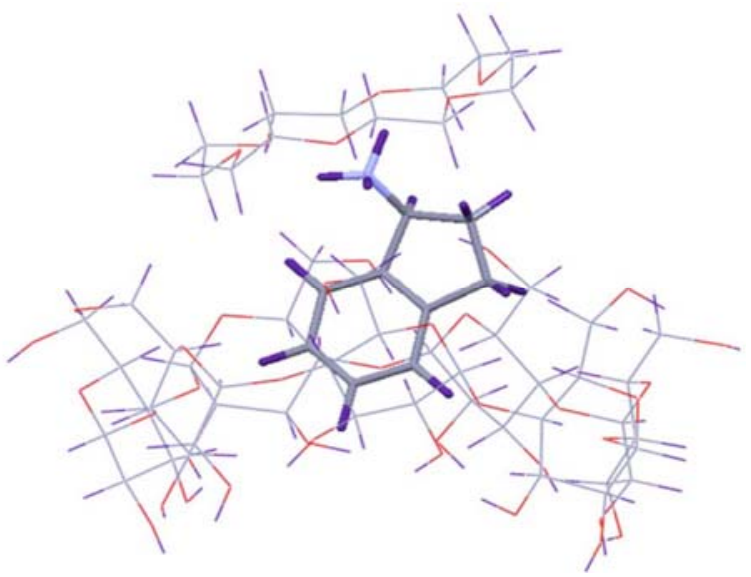

Figure 2: Geometries of the most favorable sandwich complexes of (a) R-AI, (b) S-AI with $\beta-C D$ and $18 C 6$.

mechanics calculations using Autodock in conjunction with quantum mechanical calculation using PM6 semiempirical method and molecular dynamics simulations were performed to rationalize the experimental results and to explain the mechanism of separation. Molecular modeling simulations of the complexes in aqueous media supported the results obtained by PM6 calculations suggesting that the differences in stabilities of diastereomers lead to the observed separation.

\section{CONCLUSION}

Work published in recent years has clearly documented the potential of capillary electrophoresis and molecular modeling for an understanding of enantioselective recognition mechanisms. The most useful using of molecular modeling in enantioselective recognition mechanisms will be the calculation of intermolecular forces.

Molecular modeling studies when used in combination with CE provides a good perspective of enantioseparation and serves as a useful method for studying chiral recognition mechanisms and predicting chiral separation.

\section{REFERENCES}

[1] Nunez-Aguero CJ, Escobar-Llanos CM, Diaz D, Jaime C, Garduno-Juarez R. Chiral discrimination of ibuprofen isomers in $\beta$-cyclodextrin inclusion complexes: experimental (NMR) and theoretical (MD, MM/GBSA) studies. Tetrahedron 2006; 62: 4162-72.

http://dx.doi.org/10.1016/j.tet.2006.02.010

[2] Rizzi A. Fundamental aspects of chiral separations by capillary electrophoresis. Electrophoresis 2001; 22: 3079106.

http://dx.doi.org/10.1002/15222683(200109)22:15<3079::AID-ELPS3079>3.0.CO;2-F
[3] Jun $\mathrm{H}$. Enantiomer separation of drugs by capillary electrophoresis using proteins as chiral selectors. J Chromatogr A 2000; 875: 235-54. http://dx.doi.org/10.1016/S0021-9673(99)01168-1

[4] Fanli S. Enantioselective determination by capillary electrophoresis with cyclodextrins as chiral selectors. J Chromatogr A 2000; 875: 89-122.

[5] Harris DC. Quantitative Chemical Analysis, $8^{\text {th }}$ ed., W. H. Freeman, New York 2010.

[6] Rizzi AM, Kremser L. pK(a) shift-associated effects in enantioseparations by cyclodextrin- mediated capillary zone electrophoresis. Electrophoresis 1999; 20: 2715-22. http://dx.doi.org/10.1002/(SICI)15222683(19990901)20:13<2715::AID-ELPS2715>3.0.CO;2-E

[7] Chankvetadze B, Linder W, Scriba GKE. Enantiomer separations in capillary electrophoresis in the case of equal binding constants of the enantiomers with a chiral selector: Commentary on the feasibility of the concept. Anal Chem 2004; 76: 4256-60.

http://dx.doi.org/10.1021/ac0355202

[8] Chankvetadze B. Enantioseparations by using capillary electrophoretic techniques. The story of 20 and a few more years. J Chromatogr A 2007; 1168: 45-70. http://dx.doi.org/10.1016/j.chroma.2007.08.008

[9] Scriba GKE. Cyclodextrins in capillary electrophoresis enantioseparations - Recent developments and applications. J Sep Sci 2008; 31: 1991-11. http://dx.doi.org/10.1002/jssc.200800095

[10] Chaudhuri S, Chakraborty S, Sengupt PK. Encapsulation of serotonin in $\beta$-cyclodextrin nano-cavities: Fluorescence spectroscopic and molecular modeling studies. J Mol Struct 2010; 975: 160-65.

http://dx.doi.org/10.1016/i.molstruc.2010.04.014

[11] Chakraborty S, Bas S, Lahiri A, Basak S. Inclusion of chrysin in $\beta$-cyclodextrin nanocavity and its effect on antioxidant potential of chrysin: A spectroscopic and molecular modeling approach. J Mol Struct 2010; 977: 180-8. http://dx.doi.org/10.1016/j.molstruc.2010.05.030

[12] Waibel B, Scheiber J, Meier C, Hammitzsch M, Baumann K, Scriba GKE, et al. Comparison of cyclodextrin-dipeptide inclusion complexes in the absence and presence of urea by means of capillary electrophoresis, nuclear magnetic resonance and molecular modeling. Eur $\mathrm{J}$ Org Chem 2007; 18: 2921-30. http://dx.doi.org/10.1002/ejoc.200700052

[13] Wei K, Luo S-W, Fu Y, Liu L, Guo Q-X. A theoretical study on bond dissociation energies and oxidation potentials of monolignols. J Mol Struct: Theochem 712: 197-205; 60: 81520. 
[14] Carofiglio T, Fornasier R, Jicsinszky L, Saielli G, Tonellato U, Vetta R. Capillary electrophoresis, ROESY NMR and molecular modelling study of the inclusion complex $\beta$ cyclodextrin/lipoic acid. Eur J Org Chem 2002; 7: 1191-96. http://dx.doi.org/10.1002/10990690(200204)2002:7<1191::AID-EJOC1191>3.0.CO;2-I

[15] Yan C, Xiu Z, Li X, Hao C. Molecular modeling study of $\beta$ cyclodextrin complexes with (+)-catechin and (-)-epicatechin. J Mol Graph Model 2007; 26: 420-28. http://dx.doi.org/10.1016/j.jmgm.2007.01.010

[16] Jullian C, Brossard V, Gonzalez I, Alfaro M, Olea-Azar C. Cyclodextrins-kaempferol inclusion complexes: Spectroscopic and reactivity studies. J Solut Chem 2011: 727.

[17] Deng Y, Huang M-JU. Capillary electrophoretic separation and theoretical study of inclusion complexes of sulfobutyl ether $\beta$-cyclodextrin with estrogens. Int J Quantum Chem 2004; 100: 746-52. http://dx.doi.org/10.1002/qua.20239

[18] Dos Santos HF, Duarte HA, Sinisterra RD, De Melo Mattos SV, De Oliveria LC, De Almeida WB. Quantum-mechanical study of the interaction of $\alpha$-cyclodextrin with methyl mercury chloride. Chem Phys Lett 2000; 319: 569-75. http://dx.doi.org/10.1016/S0009-2614(00)00087-7

[19] Eid EEM, Bustam AB, Suliman FEO, Sukari MA, Rasedee A, Fatah SS. Characterization of the inclusion complex of zerumbone with hydroxypropyl- $\beta$-cyclodextrin. Carbohydr 2011; 83: 1707-14.

http://dx.doi.org/10.1016/j.carbpol.2010.10.033

[20] Bikadi Z, Fodor G, Hazai I, Hari P, Szeman J, Szente L, et al. Molecular modeling of enantioseparation of phenylazetidin derivatives by cyclodextrins. Chromatographia 2010; 71: S21.

http://dx.doi.org/10.1365/s10337-009-1461-9

[21] Hameed AJM, Ibrahimb M, ElHaesc H. Computational notes on structural, electronic and QSAR properties of Fulleropyrrolidine-1-carbodithioic acid 2; 3 and 4-substitutedbenzyl esters. J Mol Struct- Theochem 2007; 809: 131-36. http://dx.doi.org/10.1016/j.theochem.2007.01.021

[22] Essa AH, Ibrahim M, Ali Jameel Hameed AJ, Al-Masoudi NA. Theoretical investigation of 3'-subtituted-2'-3'dideoxythymidines related to AZT QSAR infrared and substituent electronic effect studies" ARKIVOC (xiii) 2008; 255-65.

[23] Ibrahim M, Saleh NA, Hameed AJ, Elshemey WM, Elsayed Structural and Electronic Properties of new Fullerene Derivatives and their Possible Application as HIV-1 Protease Inhibitors A.A. Spectrochimica Acta Part A 2010; 75: 702709. http://dx.doi.org/10.1016/j.saa.2009.11.042

[24] Ibrahim M, Mahmoud AA, Osman O, Abd El-Aal M, Eid M. Molecular Spectroscopic Analyses of Gelatin. Spectrochimica Acta Part A 2011; 81: 724-29.

http://dx.doi.org/10.1016/j.saa.2011.07.012

[25] Ibrahim M, Saleh NA, Elshemey WM, Elsayed AA. Fullerene Derivative as anti-HIV Protease Inhibitor: Molecular Modeling and QSAR Approaches. Mini Rev Med Chem 2012; 12: 44751. http://dx.doi.org/10.2174/138955712800493762

[26] Li Z, Couzijn EPA, Zhang X. Intrinsic properties of $\alpha$ cyclodextrin complexes with benzoate derivatives in the gas phase: An experimental and theoretical study. J Phys Chem B 2012; 116: 943-50.

http://dx.doi.org/10.1021/jp210329a

[27] Li W, Lu B, Chen F, Yang F, Wang Z. Host-guest complex of cypermethrin with $\beta$-cyclodextrin: A spectroscopy and theoretical investigation. J Mol Struct 2011; 990: 244-52. http://dx.doi.org/10.1016/j.molstruc.2011.01.053
[28] Liu P, Zhang D, Zhan J. Investigation on the inclusions of PCB52 with cyclodextrins by performing DFT calculations and molecular dynamics simulations. J Phys Chem A 2010; 114: 13122-28.

http://dx.doi.org/10.1021/jp109306v

[29] Khedkar JK, Gobre VV, Pinjari RV, Gejji SP. Electronic structure and normal vibrations in (+)-catechin and (-)epicatechin encapsulated $\beta$-cyclodextrin. J Phys Chem A 2010; 114: 7725-32.

http://dx.doi.org/10.1021/jp102304j

[30] Kahle C, Deubner R, Schollmayer C, Scheiber J, Baumann K, Holzgrabe U. NMR spectroscopic and molecular modelling studies on cyclodextrin-dipeptide inclusion complexes. Eur $\mathrm{J}$ Org Chem 2005; 8: 1578-89.

http://dx.doi.org/10.1002/ejoc.200400673

[31] Stewart JJP. Optimization of parameters for semiempirical methods V: Modification of NDDO approximations and application to 70 elements. J Mol Model 2007; 13: 1173-13. http://dx.doi.org/10.1007/s00894-007-0233-4

[32] Lipkowitz KB. Atomistic modeling of enantioselection: Applications in chiral chromatography. Theor Comput Chem 1998; 5: 329-79. http://dx.doi.org/10.1016/S1380-7323(98)80013-7

[33] Lipkowitz KB. Atomistic modeling of enantioselection in chromatography. J Chromatogr A 2001; 906: 417-42. http://dx.doi.org/10.1016/S0021-9673(00)00946-8

[34] Lammerhofer M. Chiral recognition by enantioselective liquid chromatography: Mechanisms and modern chiral stationary phases. J Chromatogr A 2010; 1217: 814-56.

http://dx.doi.org/10.1016/j.chroma.2009.10.022

[35] Bikádi Z, Fodor G, Hazai I, Hári P, Szemán J, Szente L, et al. Molecular modeling of enantioseparation of phenylazetidin derivatives by cyclodextrins. Chromatographia 2010; 71: S21-S28.

http://dx.doi.org/10.1365/s10337-009-1461-9

[36] Zhou ZM, Li X, Chen XP, Fang M, Dong X. Separation performance and recognition mechanism of mono(6-deoxyimino)- $\beta$-cyclodextrins chiral stationary phases in highperformance liquid chromatography. Talanta 2010; 82: 77584

http://dx.doi.org/10.1016/j.talanta.2010.05.052

[37] Li X, Zhou ZM, Xu D, Zhang J. Enantiomeric separation in high-performance liquid chromatography using novel $\beta$ cyclodextrin derivatives modified by R-configuration groups as chiral stationary phases. Talanta $2011 ; 84: 1080-92$. http://dx.doi.org/10.1016/j.talanta.2011.03.023

[38] Shi JH, Ding ZJ, Hu Y. Experimental and theoretical studies on the enantioseparation and chiral recognition of mandelate and cyclohexylmandelate on permethylated $\beta$-Cyclodextrin chiral stationary phase. Chromatographia 2011; 74: 319-25. http://dx.doi.org/10.1007/s10337-011-2069-4

[39] Shi JH, Ding ZJ, Hu Y. Theoretical study on chiral recognition mechanism of methyl mandelate enantiomers on permethylated $\beta$-cyclodextrin. J Mol Model 2012; 18: 80313. http://dx.doi.org/10.1007/s00894-011-1118-0

[40] Bednarek E, Bocian W, Michalska K. NMR and molecular modeling study, as complementary techniques to capillary electrophoresis method to elucidate the separation mechanism of linezolid enantiomers. J Chromatogr A 2008; 1193: 164-71. http://dx.doi.org/10.1016/j.chroma.2008.04.008

[41] Michalska K, Pajchel G, Tyski S. NMR and molecular modeling study, as complementary techniques to capillary electrophoresis method to elucidate the separation mechanism of linezolid enantiomers. J Chromatogr A 2008; 1180: 179-86.

http://dx.doi.org/10.1016/j.chroma.2007.11.110 
[42] Huang M-J, Quan Z, Liu Y-M. Computational modeling of inclusion complexes of $\beta$-cyclodextrin with enantiomers of salsolinol, N-methylsalsolinol, and 1-benzyltetrahydroisoquinoline. Int J Quantum Chem 2009; 109: 8190 . http://dx.doi.org/10.1002/qua.21852

[43] Kim H, Choi Y, Kim J-I, Jeong K, Jung S. Orientations of Polycrystalline $\mathrm{ZnO}$ at the Buried Interface of Oxide Thin Film Transistors (TFTs): A Grazing Incidence X-ray Diffraction Study. Bull Korean Chem Soc 2009; 30: 1373.

[44] Mofaddel N, Adoubel AA, Morin CJ, Desbène P-L, Dupas G. Molecular modeling of complexes between two amino acids and copper(II): Correlation with Ligand Exchange Capillary Electrophoresis. J Mol Struct 2010; 975: 220-6. http://dx.doi.org/10.1016/j.molstruc.2010.04.027

[45] Aït Adoubel A, Morin CJ, Mofaddel N, Dupas G, Desbène P$\mathrm{L}$. Enantioseparation of underivatised amino acids by ligand exchange capillary electrophoresis in a counterelectroosmotic mode. Anal Bioanal Chem 2009; 394: 597608.

http://dx.doi.org/10.1007/s00216-009-2694-Z

[46] Zhang G, Sun Q, Hou Y, Hong Z, Zhang J, Zhao L, et al. New mathematic model for predicting chiral separation using molecular docking: Mechanism of chiral recognition of triadimenol analogues. J Sep Sci 2009; 32: 2401-407. http://dx.doi.org/10.1002/jssc.200900012

[47] Sohajda T, Béni S, Varga E, Iványi R, Rácz A, Szente L, et al. Characterization of aspartame-cyclodextrin complexation. J Pharm Biomed Anal 2009; 50: 737-45. http://dx.doi.org/10.1016/j.jpba.2009.06.010

[48] Elbashir AA, Suliman FEO, Saad B, Aboul-Enein HY. Determination of aminoglutethimide enantiomers in pharmaceutical formulations by capillary electrophoresis using methylated- $\beta$-cyclodextrin as a chiral selector and computational calculation for their respective inclusion complexes. Talanta 2009; 77: 1388-93. http://dx.doi.org/10.1016/j.talanta.2008.09.029

[49] Elbashir AA, Suliman FEO, Saad B, Aboul-Enein HY. Capillary electrophoretic separation and computational modeling of inclusion complexes of $\beta$-cyclodextrin and 18crown-6 ether with primaquine and quinocide. Biomed Chromatogr 2010; 24: 393-8.

[50] Elbashir AA, Saad B, Ali ASM, Saleh MI, Aboul-Enein HY. Determination of quinocide as impurity in primaquine tablets by capillary zone electrophoresis. Biomed Chromatogr 2009; 23: 464-71. http://dx.doi.org/10.1002/bmc.1137

[51] Al Azzam KM, Saad B, Adnan R, Saleh MI. Enantioselective determination of modafinil in pharmaceutical formulations by capillary electrophoresis, and computational calculation of their inclusion complexes. Microchimica Acta 2009; 166: 3117. http://dx.doi.org/10.1007/s00604-009-0209-4
[52] Al Azzam KM, Saad B, Adnan R, Aboul-Enein HY. Hollow fiber liquid-phase microextraction for the determination of trace amounts of rosiglitazone (anti-diabetic drug) in biological fluids using capillary electrophoresis and high performance liquid chromatographic methods. Anal Chim Acta 2010; 674: 249-55.

http://dx.doi.org/10.1016/j.aca.2010.06.046

[53] Holm R, Schönbeck C, Askjær S, Jensen H, Østergaard J. Complexation of tauro- and glyco-conjugated bile salts with $\alpha$-cyclodextrin and hydroxypropyl- $\alpha$-cyclodextrin studied by affinity capillary electrophoresis and molecular modelling. $J$ Sep Sci 2011; 34: 3221-30. http://dx.doi.org/10.1002/jssc.201100479

[54] Elbashir AA, Suliman FO. Computational modeling of capillary electrophoretic behavior of primary amines using dual system of 18 -crown- 6 and $\beta$-cyclodextrin. J Chromatogr A 2011; 1218: 5344-51. http://dx.doi.org/10.1016/j.chroma.2011.06.030

[55] Li W, Liu C, Tan G, Zhang X, Zhu Z, Chai Y. Molecular modeling study of chiral separation and recognition mechanism of $\beta$-adrenergic antagonists by capillary electrophoresis. Int J Mol Sci 2012; 13: 710-25. http://dx.doi.org/10.3390/ijms 13010710

[56] Li W, Zhao L, Tan G, Sheng C, Zhang X, Zhu Z, et al. Enantioseparation of the new antifungal drug iodiconazole and structurally related triadimenol analogues by $\mathrm{CE}$ with neutral cyclodextrin additives. Chromatographia 2011; 73: 1009-14. http://dx.doi.org/10.1007/s10337-010-1897-y

[57] Li W, Tan G, Zhao L, Chen X, Zhang X, Zhu Z, et al. Computer-aided molecular modeling study of enantioseparation of iodiconazole and structurally related triadimenol analogues by capillary electrophoresis: Chiral recognition mechanism and mathematical model for predicting chiral separation. Analytica Chimica Acta 2012; 718: 138-47.

http://dx.doi.org/10.1016/i.aca.2012.01.007

[58] Servais A-C, Rousseau A, Dive G, Frederich M, Crommen J, Fillet M. Combination of capillary electrophoresis, molecular modelling and nuclear magnetic resonance to study the interaction mechanisms between single-isomer anionic cyclodextrin derivatives and basic drug enantiomers in a methanolic background electrolyte. J Chromatogr A 2012; 1232: 59-64.

http://dx.doi.org/10.1016/j.chroma.2011.10.010

[59] Suliman FO, Elbashir AA. Enantiodifferentiation of chiral baclofen by $\beta$-cyclodextrin using capillary electrophoresis: $A$ molecular modeling approach. J Mol Struct 2102; 1019: 4349. 